\title{
Risk Factors of Metabolic Bone Disease in Bronchopulmonary Dysplasia Premature Infants With Gestational Age Less Than 32 Weeks
}

\section{Wenwen Chen}

Zhangzhou Hospital Affiliated to Fujian Medical University

\section{Zhenghai Zhang}

zhangzhou Hospital Affiliated to Fujian Medical University

Shuzhen Dai

Zhangzhou Hospital Affiliated to Fujian Medical University

Xu Liping ( $\nabla$ zzsyxlp@163.com )

Fujian Medical University https://orcid.org/0000-0002-0296-0019

Research article

Keywords: MBD, BPD, preterm, risk factors

Posted Date: October 12th, 2020

DOI: https://doi.org/10.21203/rs.3.rs-89304/v1

License: (a) (i) This work is licensed under a Creative Commons Attribution 4.0 International License.

Read Full License 


\section{Abstract}

\section{Background}

Metabolic bone disease (MBD) is a complication of multifactorial aetiology in preterm infants. Several risk factors have been identified in general. Bronchopulmonary Dysplasia (BPD) infants present an increased incidence of MBD, but it is unknown which factors contribute to this. The aim of this study was to determine the risk factors for developing MBD in BPD infants.

\section{Methods}

A retrospective review of the medical records of BPD infants admitted to the Neonatal Intensive Care Unit (NICU) at Zhangzhou Hospital between Jun 2016 and May 2020. BPD infants with MBD were identified, two contemporaneous without MBD matched by gestational age and gender were randomly selected as control infants for each case of MBD. The association between putative risk factors and MBD was estimated with ORs and $95 \%$ Cls. A $P$-value threshold $\leq 0.2$ was used in univariate analysis for inclusion into a multivariate (adjusted) model with a $P$-value of $<0.05$ as statistically significant.

Results

A total of 156 BPD infants were enrolled with 52 cases of MBD and 104 controls. Fetal growth restriction (OR 5.60, 95\% Cl, 1.77-17.72), extremely low birth weight (OR 3.70, 95\% Cl, 1.35-10.10), feeding volume $\nabla 80 \mathrm{~mL} / \mathrm{kg} /$ day at the end of the 4th week after birth (OR 12.21, 95\% Cl, 3.89-38.33), cholestasis (OR $4.29,95 \% \mathrm{Cl}, 1.65-11.15)$, and late onset sepsis (OR 3.79, 95\% Cl, 1.12-12.77) were found to be statistically significant risk factors for MBD in BPD infants.

\section{Conclusion}

In gestational age homogeneous BPD infants, fetal growth restriction, extremely low birth weight, feeding volume $\varangle 8 \mathrm{~mL} / \mathrm{kg} /$ day at the end of the 4th week after birth and late onset sepsis are significant risk factors for MBD. These findings provide potential predictive factors for MBD in BPD infants but still warrant prospective validation.

\section{Introduction}

Metabolic Bone Disease (MBD) of prematurity is a multifactorial disorder characterized by low bone mass and demineralization of bone tissue posing a consequent increase in bone fragility and long-term reduced linear growth and childhood or even adult height, which is commonly observed in very low birth weight (VLBW, $<1,500 \mathrm{~g}$ ), especially in extremely low birth weight (ELBW, $<1,000 \mathrm{~g}$ ) infants with a reported incidence of about $16 \%-40 \%$ [1]. BPD infants have a higher incidence $(60 \%$ vs $34 \%$, compared with infants without BPD) of MBD in infants $\varangle 1,250 \mathrm{~g}$ [2]. Among infants born $\otimes 1,500 \mathrm{~g}$ suffered from severe $\mathrm{BPD}$, about one third developed severe MBD [3]. 
Several factors associated with increased risk of MBD had been identified. Costa $\mathrm{R}$ et al found that the majority of MBD infants were male and presented lower gestational age, lower birth weight, and prolonged duration of parenteral nutrition [4]. Chen $W$ et al found that birth at $<30$ weeks of gestation, vitamin $D$ supplementation at $>14$ days of age, and achievement of total enteral nutrition (TEN) beyond 28 days of age were independent risk factors for MBD in infants $₫ 34$ weeks gestational age [5]. Montaner Ramón A et al pointed only restricted fetal growth was independently associated with the development of severe MBD (OR 9.65, 95\% Cl 3.48-26.76) in infants $₫ 32$ weeks gestational age and/or weight $₫ 1,500 \mathrm{~g}$ [6], and Ukarapong $\mathrm{S}$ et al indicated that only cholestasis remained significantly risk factors $(\mathrm{OR} 9.6,95 \% \mathrm{Cl}$ 2.1-45.3) in infants $<30$ weeks gestational age and/or weight $<1,000 \mathrm{~g}$ [7]. Although BPD infants presented an increased risk for developing MBD, previous studies did not evaluate the risk factors that would be associated with MBD in BPD infants.

The purpose of this study was to assess the risk factors for MBD in BPD infants, which might contribute to identify high-risk individuals and propose further recommendations for management of the comorbidities.

\section{Materials And Methods}

Study population and setting

We performed a retrospective review of the medical records of BPD infants admitted to the Neonatal Intensive Care Unit (NICU) at Zhangzhou Hospital between Jun 2016 and May 2020. The study was approved by the Institutional Review Board of the Zhangzhou Hospital, with waiver of informed consent. Case with MBD were identified as case group. Inclusion criteria consisted of the following: (1) gestational age $₫ 32$ weeks, (2) survival up to 36 weeks post-menstrual age (PMA), (3) diagnosis of BPD according to National Institutes of Health $(\mathrm{NIH})$ that defined as requirement of oxygen support $(>21 \%)$ for at least 28 days and a subsequent assessment at 36 weeks PMA or discharge, whichever comes first. At the time of assessment, infants with no oxygen requirement were classified as having mild BPD, infants requiring $<30 \%$ oxygen were classified as having moderate BPD and infants with a need for positive pressure ventilation/continuous positive pressure (PPV/CPAP) and/or oxygen requirement $\geq 30 \%$ were classified as having severe BPD [8], and (4) diagnosis of MBD that defined as peak serum ALP higher than $900 \mathrm{U} / \mathrm{L}$ and serum phosphate level lower than $1.8 \mathrm{mmol} / \mathrm{L}$, which yielded a sensitivity of $100 \%$ at a specificity of $70 \%$, with or without radiographic changes of long bones [9]. Exclusion criteria included the following: (1) gestational age $\geq 32$ weeks, (2) presence of significant congenital anomalies, (3) death before 36 weeks PMA. For each MBD case, two contemporaneous with BPD but without MBD matched at equivalent gestational age and gender (male: female $=1: 1$ ) were randomly selected.

Clinical data on demographics and putative risk factors for MBD were collected, including birth weight, gender, use of antenatal steroids, histologic chorioamnionitis (HCA), fetal growth restriction (FGR), maternal hypertensive disorders without FGR, prolonged rupture of membranes (PROM), type of feeding, initiation of oral vitamin D supplementation, feeding volume at the end of the $4^{\text {th }}$ week after birth, 
postnatal dexamethasone application, patent ductus arteriosus (PDA), cholestasis, use of mechanical ventilation, late onset sepsis (LOS), thyroid function tests and platelet (PLT) count.

FGR was defined as antenatal diagnosis by any 2 of the following: estimated fetal weight below the 10th percentile according to the care provider reference curve, abnormal fetal Doppler findings, growth arrest, or maternal hypertensive disorders. PROM was defined as rupture of the membranes occurring earlier than $24 \mathrm{~h}$ before delivery [10]. HCA was defined as the infiltration of neutrophils in any of the following structures: placental disc, the chorioamniotic membranes, and the umbilical cord [11]. Cholestasis was defined as direct bilirubin $>2 \mathrm{mg} / \mathrm{dL}$ [12]. Maternal hypertensive disorder was defined as systolic blood pressure $\geq 140 \mathrm{mmHg}$ and (or) diastolic blood pressure $\geq 90 \mathrm{mmHg}$ [13]. PDA was diagnosed with echocardiography confirmation. Thyroid-stimulating hormone $(\mathrm{TSH})=10 \mathrm{mU} / \mathrm{L}$ was used as the cutoff level for hypothyroidism [14] and PLT $1100 \times 10^{\wedge} 5 / L$ was considered to be thrombocytopenia [15]. LOS was diagnosed with clinical suspicion and evaluated by microbial culture or two non-specific blood indicators occurring after $72 \mathrm{~h}$ of birth $[16,17]$.

In our NICU, we started parenteral nutrition in the first hours after birth and introduced enteral feeding with breast milk as soon as the infant reached a tolerated respiratory rate without hemodynamic instability. The amount increased gradually with a rate of $20-30 \mathrm{~mL} / \mathrm{kg} /$ day without signs of feeding intolerance. Oral vitamin D (800-1000 IU) supplementation was started when the amount of breast milk feed reaches $50 \mathrm{~mL} / \mathrm{kg} /$ day, and liquid human milk fortification was added when the amount of breast milk feed reaches $80 \mathrm{~mL} / \mathrm{kg} /$ day. Premature formula was also used if the amount of breast milk is insufficient.

Statistical Analyses

Data were analyzed using SPSS version 26. Dichotomous or categorical variables were compared between cases and controls with the use of $\chi 2$ analysis or the Fisher exact test or $z$-test. Continuous variables were compared between groups via the Mann-Whitney $U$ test. A risk model was derived via logistic regression, with $95 \%$ Cls calculated for ORs using the forward LR method. A $P$-value of $\leq 0.2$ was used in univariate analysis for inclusion of putative risk factors into the multivariate (adjusted) model. A $P$-value of $<0.05$ was considered statistically significant [16].

\section{Results}

During the study period, a total of 156 infants with BPD were enrolled with 52 cases of MBD and 104 controls. Demographic and clinical characteristics among cases with MBD and controls was shown in Table 1. There is no significant difference between the two groups in the distribution of BPD severity (mild BPD $59.6 \%$ vs. $70.2 \%$; moderate BPD $23.1 \%$ vs $21.2 \%$; severe BPD $17.3 \%$ vs $8.7 \%$ in MBD cases and controls respectively; $P=0.236)$.

Univariate logistic regression analyses (Table 2) revealed that, among the putative risk factors evaluated, FGR (OR 6.16, 95\% Cl, 2.34-16.20) खextremely low birth weight (ELBW, birth weight $\ 1000 \mathrm{~g})$ (OR 2.28, 95\% $\mathrm{Cl}, 1.04-5.00)$, feeding volume $\otimes 80 \mathrm{~mL} / \mathrm{kg} /$ day at the end of the $4^{\text {th }}$ week after birth $(\mathrm{OR} 13.00,95 \% \mathrm{Cl}$, 
4.82-34.84), cholestasis (OR 3.50, 95\% Cl, 1.66-7.41), and LOS (OR 3.60, 95\% Cl, 1.37-9.47) were all statistically significantly associated with development of MBD in BPD. After adjustment in multiple logistic regression, each of these remained as statistically significant, independent risk factors for MBD (FGR [OR 5.60, 95\% Cl, 1.77-17.72], ELBW [OR 3.70, 95\% Cl, 1.35-10.10]), feeding volume $880 \mathrm{~mL} / \mathrm{kg} /$ day at the end of the $4^{\text {th }}$ week after birth [OR $12.21,95 \% \mathrm{Cl}, 3.89-38.33$ ], cholestasis [OR $4.29,95 \% \mathrm{Cl}, 1.65-$ 11.15], LOS [OR 3.69, 95\% Cl, 1.12-12.77]).

\section{Discussion}

The growing advances in the intensive care of preterm infants have led to a decrease in mortality, but cause more frequent morbidity such as MBD and BPD, etc. Previous studies have proved that MBD is inversely associated with gestational age $[4,5]$, hence we matched the gestational age equal to the cases when selecting the controls to allow evaluating other putative factors in homogeneous groups. This study provides novel data on risk factors for MBD in BPD infants. FGR, ELBW (birth weight $₫ 1000 \mathrm{~g}$ ), feeding volume $\mathbb{8} 8 \mathrm{~mL} / \mathrm{kg} /$ day at the end of the $4^{\text {th }}$ week after birth, cholestasis and LOS each served as statistically significant, independent risk factors, on the basis of their associated ORs from multiple logistic regression.

The association between FGR and MBD in BPD infants was confirmed in our study which also in accordance with other data showing that FGR was a risk factor for BPD published [8]. This early life factor seemed to ease MBD development in a programmed process and might be used as an early predictive indicator for screening of MBD. FGR commonly coexists with preeclampsia at gestation, which results in placental abnormalities that deteriorates placental transfer of calcium, magnesium and phosphorus [19], and thus contribute to MBD. Furthermore, our study showed that maternal hypertensive disorder without FGR was not associated with MBD, indicating the disrupted placental as key pathogenesis. In addition to FGR, ELBW was also an independent risk factor for MBD in BPD infants of equal gestational age in our study samples, revealing an inverse association between birth weight and MBD, which was found even in ELBWs exclusively by Viswanathan $S$ et al [20].

Feeding problems are almost inevitable in the very preterm infants. Generally, it is not difficult to introduce enteral feeding but hard to reach total enteral feeding owing to uncomfortable abdominal distention or signs of necrotizing enterocolitis (NEC), which may disrupt the feeding schedule. Prolonged PN were demonstrated to associated with MBD by several researches elsewhere [21]. Similarly our study revealed that an enteral feeding volume $80 \mathrm{~mL} / \mathrm{kg} / \mathrm{d}$ at the end of the $4^{\text {th }}$ week after birth remarkably increased the risk for MBD in BPD infants. This may be explained by the following reasons. First, the small breastfed volume did not allow the introduce of breast milk fortifier in our NICU. Breast milk provides inadequate protein and mineral content which cannot guarantee enough calcium and phosphate intake for preterm infants. Second, the sufficient feeding volume still require PN supplement which pose the possibility of aluminum contamination and the risk of mineral precipitation in the solution due to the small volumes [22]. It has been demonstrated that newborns fed exclusively with breast milk showed lower levels of phosphate [23] and fortified breast milk feeding significantly increase bone mineral 
density (BMD) values via linear regression analysis [24]. Therefore, an earlier begin of fortification of the breast milk begins might be taken into consideration in breast-fed preterm infants with high risk for BPD, as appropriate. Some studies showed that vitamin D supplementation at $>14$ days of age was also associated with MBD, however, our study did not consistent with it. A possible explanation is that it is the blood levels of 25(OH)D3 that is directly associated with MBD [6]. A usual intake dose of $800-1000 \mathrm{IU} / \mathrm{d}$ for preterm infants with BPD did not achieve the protective level, which is probable due to fat-soluble vitamin deficiency caused by the coexisting cholestasis [25]. Simultaneously, cholestasis was also a risk factor for MBD in BPD infants confirmed by our study and other researches [21]. In other words, these infants may be at a greater demand for vitamin $D$ supplementation.

LOS remains an important problem and are associated with complications of preterm infants including BPD [27]. Jensen EA et al found that blood culture confirmed sepsis were associated with increased odds of severe MBD in infants with severe BPD [28]. Our study reenforced the association between LOS and MBD in BPD infants. It has been acknowledged that important interactions occur between immune and skeletal systems [29]. Lipopolysaccharide exposures could result in bone loss [30], which might be due to the activation of $B$ and $T$ cells that potentially regulate bone resorption [29]. Approaches, such as a strict hygiene protocol and the minimization of invasive procedures in NICUs should be employed in prevention of LOS in order to reduce MBD.

The strengths of this study are as follows, first, we enrolled only infants with BPD and matched gestational age to ensure the comparison in homogeneous groups, second, the monocentric study guaranteed that the enrollments were managed strictly under the same perinatal practices including diagnosis and treatments. Still, there are some limitations. MBD is a multifactorial disease. The small sample size may mask some risk factors that could not be displayed. However, we determine some risk factors that could be interpreted. The results in our study revealed that MBD in BPD infants shared some same risk factors with preterm infants in general.

\section{Conclusion}

In gestational age homogeneous BPD infants, fetal growth restriction, ELBW, feeding volume $₫ 80$ $\mathrm{mL} / \mathrm{kg} /$ day at the end of the $4^{\text {th }}$ week after birth and LOS are significant risk factors for MBD. Given the observational nature of this study, further longitudinal/prospective studies are required to validate these findings.

\section{Abbreviations}

MBD Metabolic bone disease

BPD Bronchopulmonary dysplasia

HCA Histologic chorioamnionitis 
FGR Fetal growth restriction

ELBW Extremely low birth weight

VLBW Very low birth weight

PROM Prolonged rupture of membranes

PDA Patent ductus arteriosus

LOS Late onset sepsis

PMA Post-menstrual age

NICU Neonatal intensive care unit

OR Odds ratio

aOR Adjusted odds ratio

$\mathrm{Cl}$ Confidence interval

\section{Declarations}

\section{Acknowledgements}

This work was completed at the Department of Neonatology, Zhangzhou Hospital Affiliated to Fujian Medical University. The authors thank all colleagues for their help in the process.

\section{Authors' contributions}

Xu LP had primary responsibility for the study design and protocol development. Chen WW performed the final data analyses and contributed to the writing of the manuscript. Zhang ZH was involved in the data collection. Dai SZ was involved in the table drawing. All authors read and approved the final manuscript.

\section{Funding}

The study was supported by Startup Fund for scientific research of Fujian Medical University (no.2019QH1270).

\section{Ethics approval and consent to participate}

The study was approved by the Institutional Review Board of the Zhangzhou Hospital. The study is based on register data, and individual informed consent from each participant is not required by waiver from the ethical committee and national guidelines. 


\section{Consent for publication}

Not applicable.

\section{Competing interests}

None declared.

\section{Availability of data and materials}

The datasets used and/or analyzed during the current study are available from the corresponding author on reasonable request.

\section{Contributor Information}

Liping Xu, Phone:+8613607591899, Email: zzsyxlp@163.com

Wenwen, Chen, Phone:+8615260656112, Email: pipixiu@163.com

\section{References}

1. Faienza MF, D'Amato E, Natale MP, Grano M, Chiarito M, Brunetti G, et al. Metabolic Bone Disease of Prematurity: Diagnosis and Management. Front Pediatr. 2019; 12;7:143. doi: 10.3389/fped.2019.00143. PMID: 31032241; PMCID: PMC6474071.

2. Gaio P, Verlato G, Daverio M, Cavicchiolo ME, Nardo D, Pasinato A, et al. Incidence of metabolic bone disease in preterm infants of birth weight $<1250 \mathrm{~g}$ and in those suffering from bronchopulmonary dysplasia. Clin Nutr ESPEN. 2018; 23: 234-239. doi: 10.1016/j.clnesp.2017.09.008. PMID: 29460805.

3. Jensen EA, White AM, Liu P, Yee K, Waber B, Monk HM, et al. Determinants of Severe Metabolic Bone Disease in Very Low-Birth-Weight Infants with Severe Bronchopulmonary Dysplasia Admitted to a Tertiary Referral Center. Am J Perinatol. 2016; 33(1): 107-113. doi: 10.1055/s-0035-1560043. PMID: 26295968.

4. Costa R, Franco C, Santos N, Maio P, Vieira F, Antunes S, et al. Metabolic Bone Disease of Prematurity in Very Low Birthweight Infants: Retrospective Observational Study. Acta Med Port. 2019; 32(7-8): 536-541. doi: 10.20344/amp.10994. PMID: 31445534.

5. Chen W, Yang C, Chen H, Zhang B. Risk factors analysis and prevention of metabolic bone disease of prematurity. Medicine (Baltimore). 2018; 97(42): e12861. doi: 10.1097/MD.0000000000012861. PMID: 30334994; PMCID: PMC6211899.

6. Montaner Ramón A, Fernández Espuelas C, Calmarza Calmarza P, Rite Gracia S, Oliván Del Cacho MJ. Risk factors and biochemical markers in metabolic bone disease of premature newborns. Rev Chil Pediatr. 2017; 88(4): 487-494. doi: 10.4067/S0370-41062017000400007. PMID: 28898316.

7. Ukarapong S, Venkatarayappa SKB, Navarrete C, Berkovitz G. Risk factors of metabolic bone disease of prematurity. Early Hum Dev. 2017; 112:29-34. doi: 10.1016/j.earlhumdev.2017.06.010. PMID: 
28683339.

8. Backström MC, Kouri T, Kuusela AL, Sievänen H, Koivisto AM, Ikonen RS, et al. Bone isoenzyme of serum alkaline phosphatase and serum inorganic phosphate in metabolic bone disease of prematurity. Acta Paediatr. 2000; 89(7): 867-73. PMID: 10943972.

9. Torchin H, Lorthe E, Goffinet F, Kayem G, Subtil D, Truffert P, et al. Histologic Chorioamnionitis and Bronchopulmonary Dysplasia in Preterm Infants: The Epidemiologic Study on Low Gestational Ages 2 Cohort. J Pediatr. 2017; 187:98-104.e3. doi: 10.1016/j.jpeds.2017.05.019. PMID: 28583707.

10. Kim CJ, Romero R, Chaemsaithong P, Chaiyasit N, Yoon BH, Kim YM. Acute chorioamnionitis and funisitis: definition, pathologic features, and clinical significance. Am J Obstet Gynecol. 2015; 213(4 Suppl): S29-52. doi: 10.1016/j.ajog.2015.08.040. PMID: 26428501; PMCID: PMC4774647.

11. Salvador A, Janeczko M, Porat R, Sekhon R, Moewes A, Schutzman D. Randomized controlled trial of early parenteral nutrition cycling to prevent cholestasis in very low birth weight infants. J Pediatr. 2012; 161(2): 229-233.e1. doi: 10.1016/j.jpeds.2012.02.003. PMID: 22424948.

12. Leeman L, Dresang LT, Fontaine P. Hypertensive Disorders of Pregnancy. Am Fam Physician. 2016; 93(2): 121-127. PMID: 26926408.

13. Hashemipour M, Hovsepian S, Ansari A, Keikha M, Khalighinejad P, Niknam N. Screening of congenital hypothyroidism in preterm, low birth weight and very low birth weight neonates: A systematic review. Pediatr Neonatol. 2018; 59(1): 3-14. doi: 10.1016/j.pedneo.2017.04.006. PMID: 28811156.

14. Kulkarni VV, Dutta S, Sundaram V, Saini SS. Preterm Thrombocytopenia and Delay of Ductus Arteriosus Closure. Pediatrics. 2016; 138(4):e20161627. doi: 10.1542/peds.2016-1627. PMID: 27681010.

15. Atchison CM, Arlikar S, Amankwah E, Ayala I, Barrett L, Branchford BR, et al. Development of a new risk score for hospital-associated venous thromboembolism in noncritically ill children: findings from a large single-institutional case-control study. J Pediatr. 2014; 165(4): 793-798. doi: 10.1016/j.jpeds.2014.05.053. PMID: 25064163; PMCID: PMC7269107.

16. Alcock G, Liley HG, Cooke L, Gray PH. Prevention of neonatal late-onset sepsis: a randomised controlled trial. BMC Pediatr. 2017; 17(1): 98. doi: 10.1186/s12887-017-0855-3. PMID: 28376891; PMCID: PMC5381090.

17. Viswanathan S, Khasawneh W, McNelis K, Dykstra C, Amstadt R, Super DM, et al. Metabolic bone disease: a continued challenge in extremely low birth weight infants. JPEN J Parenter Enteral Nutr. 2014 ; 38(8): 982-990. doi: 10.1177/0148607113499590. PMID: 23963689.

18. Wood CL, Wood AM, Harker C, Embleton ND. Bone mineral density and osteoporosis after preterm birth: the role of early life factors and nutrition. Int J Endocrinol. 2013; 2013: 902513. doi: 10.1155/2013/902513. PMID: 23662104; PMCID: PMC3639624.

19. Lager S, Sovio U, Eddershaw E, van der Linden MW, Yazar C, Cook E, et al. Abnormal placental CD8+ T-cell infiltration is a feature of fetal growth restriction and pre-eclampsia. J Physiol. 2020 Sep 4. doi: 10.1113/JP279532. PMID: 32886802. 
20. Viswanathan S, Khasawneh W, McNelis K, Dykstra C, Amstadt R, Super DM, et al. Metabolic bone disease: a continued challenge in extremely low birth weight infants. JPEN J Parenter Enteral Nutr. 2014; 38(8): 982-90. doi: 10.1177/0148607113499590. PMID: 23963689.

21. Lee SM, Namgung R, Park MS, Eun HS, Park KI, Lee C. High incidence of rickets in extremely low birth weight infants with severe parenteral nutrition-associated cholestasis and bronchopulmonary dysplasia. J Korean Med Sci. 2012; 27(12): 1552-1555. doi: 10.3346/jkms.2012.27.12.1552. PMID: 23255857 ; PMCID: PMC3524437.

22. Faienza MF, D'Amato E, Natale MP, Grano M, Chiarito M, Brunetti G, et al. Metabolic Bone Disease of Prematurity: Diagnosis and Management. Front Pediatr. 2019; 7: 143. doi: 10.3389/fped.2019.00143. PMID: 31032241; PMCID: PMC6474071.

23. Bandara S, Kariyawasam A. Incidence of osteopenia of prematurity in preterm infants who were exclusively fed breast milk. Early Hum Dev. 2010; 86:S18 10.1016/j.earlhumdev.2010.09.053

24. Figueras-Aloy J, Álvarez-Domínguez E, Pérez-Fernández JM, Moretones-Suñol G, Vidal-Sicart S, BotetMussons F. Metabolic bone disease and bone mineral density in very preterm infants. J Pediatr. 2014; 164(3): 499-504. doi: 10.1016/j.jpeds.2013.10.089. PMID: 24331689.

25. Samra NM, Emad El Abrak S, El Dash HH, El Said El Raziky M, El Sheikh MA. Evaluation of vitamin D status bone mineral density and dental health in children with cholestasis. Clin Res Hepatol Gastroenterol. 2018; 42(4): 368-377. doi: 10.1016/j.clinre.2017.11.010. PMID: 29551613.

26. Jensen EA, White AM, Liu P, Yee K, Waber B, Monk HM, et al. Determinants of Severe Metabolic Bone Disease in Very Low-Birth-Weight Infants with Severe Bronchopulmonary Dysplasia Admitted to a Tertiary Referral Center. Am J Perinatol. 2016; 33(1): 107-113. doi: 10.1055/s-0035-1560043. PMID: 26295968.

27. Stoll BJ, Hansen N, Fanaroff AA, Wright LL, Carlo WA, Ehrenkranz RA, et al. Late-onset sepsis in very low birth weight neonates: the experience of the NICHD Neonatal Research Network. Pediatrics. 2002; 110(2 Pt 1): 285-291. doi: 10.1542/peds.110.2.285. PMID: 12165580.

28. Jensen EA, White AM, Liu P, Yee K, Waber B, Monk HM, et al. Determinants of Severe Metabolic Bone Disease in Very Low-Birth-Weight Infants with Severe Bronchopulmonary Dysplasia Admitted to a Tertiary Referral Center. Am J Perinatol. 2016; 33(1): 107-113. doi: 10.1055/s-0035-1560043. PMID: 26295968.

29. Horowitz MC, Fretz JA, Lorenzo JA. How B cells influence bone biology in health and disease. Bone. 2010; 47(3): 472-479. doi: 10.1016/j.bone.2010.06.011. PMID: $20601290 ;$ PMCID: PMC2941392.

30. Dusad A, Thiele GM, Klassen LW, Gleason AM, Bauer C, Mikuls TR, et al. Organic dust, lipopolysaccharide, and peptidoglycan inhalant exposures result in bone loss/disease. Am J Respir Cell Mol Biol. 2013; 49(5): 829-836. doi: 10.1165/rcmb.2013-01780C. PMID: 23782057; PMCID: PMC3931104.

\section{Tables}




\begin{tabular}{|c|c|c|c|c|}
\hline \multirow{3}{*}{ Antenatal factors } & \multicolumn{2}{|c|}{ Cases } & \multicolumn{2}{|c|}{ Controls } \\
\hline & $\mathrm{n}$ & $\%$ & $\mathrm{n}$ & $\%$ \\
\hline & 52 & & 104 & \\
\hline Steroids & 37 & 71.2 & 79 & 76.0 \\
\hline HCA & 29 & 55.8 & 50 & 48.1 \\
\hline FGR & 16 & 30.8 & 7 & 6.7 \\
\hline Maternal hypertensive disorders without FGR & 5 & 9.6 & 11 & 10.6 \\
\hline PROM & 11 & 21.2 & 27 & 26.0 \\
\hline \multicolumn{5}{|l|}{ Postnatal factors } \\
\hline ELBW & 16 & 30.8 & 17 & 16.3 \\
\hline Breast milk-fed & 39 & 75.0 & 71 & 68.3 \\
\hline Initiation of oral vitamin D supplementation $\geq 2$ weeks after birth & 20 & 38.5 & 26 & 25.0 \\
\hline $\begin{array}{l}\text { Feeding volume } ₫ 80 \mathrm{~mL} / \mathrm{kg} / \mathrm{day} \text { at the end of the } 4 \text { th week after } \\
\text { birth }\end{array}$ & 23 & 44.2 & 6 & 5.8 \\
\hline Dexamethasone & 37 & 71.2 & 79 & 76.0 \\
\hline PDA & 25 & 48.1 & 47 & 45.2 \\
\hline Cholestasis & 22 & 42.3 & 18 & 17.3 \\
\hline LOS & 12 & 23.1 & 8 & 7.7 \\
\hline Mechanical ventilation & 28 & 53.8 & 57 & 54.8 \\
\hline Hypothyroidism & 15 & 28.8 & 24 & 23.1 \\
\hline Thrombocytopenia & 9 & 17.3 & 10 & 9.6 \\
\hline
\end{tabular}

MBD, Metabolic bone disease; HCA, histologic chorioamnionitis; FGR, fetal growth restriction; ELBW, extremely low birth weight; PROM, prolonged rupture of membranes; PDA, patent ductus arteriosus; LOS, late onset sepsis.

Table 2 Unadjusted OR and aOR for putative risk factors for development of MBD in BPD infants from univariate and multiple logistic regression 


\begin{tabular}{|c|c|c|c|c|c|c|c|c|}
\hline \multirow{3}{*}{ Putative risk factors } & \multicolumn{4}{|c|}{ Unadjusted } & \multicolumn{4}{|c|}{ Adjusted } \\
\hline & & $95 \%$ & $95 \%$ & & & $95 \%$ & $95 \%$ & \\
\hline & OR & $\mathrm{LCL}$ & UCL & $P$ & OR & LCL & UCL & $P$ \\
\hline \multicolumn{9}{|l|}{ Antenatal factors } \\
\hline Steroids & 0.78 & 0.37 & 1.65 & 0.517 & & & & \\
\hline $\mathrm{HCA}$ & 1.36 & 0.70 & 2.66 & 0.366 & & & & \\
\hline FGR & 6.16 & 2.34 & 16.20 & 0.001 & 5.60 & 1.77 & 17.72 & 0.003 \\
\hline $\begin{array}{l}\text { Maternal hypertensive } \\
\text { disorders without FGR }\end{array}$ & 0.90 & 0.30 & 2.74 & 0.852 & & & & \\
\hline PROM & 0.77 & 0.35 & 1.70 & 0.765 & & & & \\
\hline \multicolumn{9}{|l|}{ Postnatal factors } \\
\hline ELBW & 2.49 & 1.14 & 5.41 & 0.022 & 3.70 & 1.35 & 10.10 & 0.011 \\
\hline Breast milk-fed & 0.72 & 0.34 & 1.52 & 0.386 & & & & \\
\hline $\begin{array}{l}\text { Initiation of oral vitamin D } \\
\text { supplementation } \geq 2 \text { weeks } \\
\text { after birth }\end{array}$ & 1.98 & 0.96 & 4.05 & 0.063 & & & & \\
\hline $\begin{array}{l}\text { Feeding volume } ₫ 80 \\
\mathrm{~mL} / \mathrm{kg} / \text { day at the end of the } \\
4^{\text {th }} \text { week after birth }\end{array}$ & 12.95 & 4.82 & 34.84 & 0.001 & 12.21 & 3.89 & 38.34 & $\begin{array}{l}0.001 \\
0.9\end{array}$ \\
\hline Dexamethasone & 1.73 & 0.72 & 4.12 & 0.220 & & & & \\
\hline PDA & 1.12 & 0.58 & 2.19 & 0.733 & & & & \\
\hline Cholestasis & 3.50 & 1.66 & 7.41 & 0.001 & 4.29 & 1.65 & 11.15 & 0.003 \\
\hline LOS & 3.60 & 1.37 & 9.47 & 0.009 & 3.79 & 1.12 & 12.77 & 0.032 \\
\hline Mechanical ventilation & 0.96 & 0.49 & 1.88 & 0.909 & & & & \\
\hline Hypothyroidism & 1.35 & 0.64 & 2.87 & 0.434 & & & & \\
\hline Thrombocytopenia & 1.97 & 0.75 & 5.2 & 0.172 & & & & \\
\hline
\end{tabular}

MBD, Metabolic bone disease; HCA, histologic chorioamnionitis; FGR, fetal growth restriction; ELBW, extremely low birth weight; PROM, prolonged rupture of membranes; PDA, patent ductus arteriosus; LOS, late onset sepsis. 